\title{
Influencia de la asistencia a las guarderías sobre la morbilidad y el consumo de recursos sanitarios en niños menores de 2 años
}

\author{
G. del Castillo Aguas ${ }^{\mathrm{a}}$, A. Gallego Iborrab , JM. Ledesma Albarrán c, M. Gutiérrez Olidc, \\ G. Moreno Muñoz ${ }^{d}$, R. Sánchez Tallón e, P. Gorrotxategi Gorrotxategif, O. Pérez González ${ }^{g}$ \\ ${ }^{\circ}$ CS Carihuela. Torremolinos, Málaga. España. \\ ${ }^{b}$ CS Trinidad. Málaga. España. 'CS Delicias. Málaga. España. \\ ${ }^{\circ}$ CS Puerto de la Torre. Málaga. España. \\ eServicio de Urgencias de Pediatría. Hospital Virgen de las Nieves. Granada. España. \\ ¡CS Beraun. Rentería, Guipúzcoa. España. \\ ${ }^{8}$ Fundación IMABIS. Málaga. España.
}

Rev Pediatr Aten Primaria. 2009; I I:695-708

Guadalupe del Castillo Aguas, gdelcas@teleline.es

\begin{abstract}
Resumen
Objetivo: evaluar la influencia de la asistencia a la guardería sobre la morbilidad y el consumo de recursos sanitarios en los niños menores de 2 años.

Material y métodos: diseño: estudio longitudinal prospectivo. Centros participantes: centros de Atención Primaria, coordinados por el Grupo de Investigación de la Asociación Española de Pediatría de Atención de Primaria (AEPap). Sujetos: niños menores de 2 años que acuden a las consultas de pediatría de los centros de salud participantes. Muestra: niños nacidos entre el 1 de abril y el 30 de octubre de 2009 que cumplan los criterios de inclusión. Variables: la variable independiente será asistencia o no a la guardería. Como variables dependientes se analizarán el número y el tipo de infecciones, los tratamientos recibidos y la asistencia a centros sanitarios. Se recogerán variables de caracterización familiares y personales que pudieran actuar como factores de confusión. Recogida de datos: entrevistas realizadas en la primera visita y a los 6, 12, 18 y 24 meses de edad. Análisis estadístico: para analizar las diferencias entre el número de infecciones dependiendo de la edad del niño al entrar en la guardería se realizará un test de Anova. Para comparar el consumo de antibióticos y de broncodilatadores, así como la utilización de recursos sanitarios entre los niños que acuden a la guardería y aquellos que no lo hacen se aplicará el test de la T de Student o el test U de Mann-Whitney. Se realizará un análisis multivariante de regresión lineal paso a paso para identificar factores personales y familiares que pueden considerarse como variables predictoras del número de infecciones, controlando los posibles factores de confusión e interacciones.
\end{abstract}

Palabras clave: Guardería, Morbilidad, Recursos sanitarios.

Los autores declaran no presentar conflictos de intereses en relación con este manuscrito y el proyecto de investigación. 


\section{Abstract}

Objective: to evaluate the influence of child day-care centres on morbidity and consumption of health resources in children younger than 2 years.

Methods: design: prospective longitudinal study. Participating institutions: Primary Health Care centers, coordinated by "Grupo de Investigación de la Asociación Española de Pediatría de Atención Primaria" (AEPap) (Research Group of the Spanish Primary Care Pediatrics Association). Subjects: children aged 0 to 2 years attending pediatric appointments of the participating health centres. Sample: all children born between April 1st and October 30th, 2009, that meet the inclusion criteria. Variables: independent variable will be Child day-care center or not. As dependent variables it will be analyzed the number and type of infection, treatments received and assistance to Health Care centers. Characterization personal and family variables that could act as confounding factors will be also collected. Data collection: interviews conducted during the first visit and at 6, 12, 18 and 24 months of age. Statistical analysis: to analyze the differences between number of infections depending on age of child when entering child day-care center, an Anova test will be done. We will apply Student's T test or Mann-Whitney's $U$ test to compare antibiotic consumption, use of bronchodilators, health resource utilization among children attending child day-care center and those who don't. A multivariate lineal regression analysis will be done step by step to identify personal and family factors that may be considered as predictors of the number of infections after controlling potential confounders and interaction factors.

Key words: Child day-care centers, Morbidity, Health resources.

\section{Introducción}

La estructura actual de la sociedad española, con la incorporación de la mujer al mundo laboral, el aumento de familias monoparentales y la carga económica que supone contratar a un cuidador, favorece la asistencia de los niños a escuelas infantiles a edades cada vez más tempranas.

Según las últimas encuestas de población ${ }^{1}$, en nuestro país, el $20,7 \%$ de la población activa declara utilizar servicios especializados para el cuidado de sus hijos, con grandes variaciones entre comunidades autónomas, desde un $13 \%$ en Extremadura hasta un $28,9 \%$ en Madrid.
La guardería se convierte, por tanto, en demanda y necesidad social, y no está exenta de influir sobre la salud del ni$\tilde{n} 0^{2}$. Con frecuencia, las familias consultan al pediatra y le piden asesoramiento sobre el cuidado más idóneo para sus hijos: el uso de un centro especializado (guardería) en contraposición, en los casos que sea posible, a otras posibilidades (abuelo, otro familiar o cuidador contratado).

La guardería supone un paso importante en la socialización del niño, así como el primer contacto masivo con agentes infecciosos. La socialización precoz podría mejorar el desarrollo conductual y lingüístico de ciertos niños ${ }^{3}$. Sin embar- 
go, en el otro lado de la balanza está el aumento de la morbilidad infecciosa4

La asistencia a centros de cuidado infantil es un factor de riesgo por sí solo para el padecimiento de infecciones del tracto respiratorio superior ${ }^{5}$ e inferior ${ }^{6-8}$, así como de otitis media aguda', infecciones gastrointestinales y otras infecciones $^{10,11}$.

Un mayor número de procesos agudos lleva implícito un mayor consumo de recursos sanitarios y de medicamentos $s^{4,12,13}$. Thrane y cols. ${ }^{14}$ demostraron que el riesgo de recibir tratamiento antibiótico se duplica durante los tres primeros meses de asistencia a la guardería.

La mayoría de los estudios encontrados están realizados en otros países con sistemas educativos diferentes al nuestro. No obstante, aunque con proporciones diferentes, se mantiene el aumento de riesgo infeccioso en los escasos estudios efectuados en nuestro país ${ }^{15-17}$.

La aparición de estos cuadros infecciosos, independientemente del tipo de centro asistencial, va ligada a una serie de factores, como son: las medidas higiénicas del local y de los cuidadores, el número de niños por cuidador y sala, así como factores que dependen del propio niño. No parecen influir el sexo, la raza ni el número de horas de asistencia ${ }^{18}$.
Entre los factores dependientes del niño, la atopia adquiere un papel relevante ${ }^{6,8}$, de forma que la incidencia de infecciones respiratorias entre los niños que asisten a la guardería sería mayor en el grupo con historia familiar o personal de atopia. Aun así, cabe destacar el posible efecto beneficioso de la estimulación precoz del sistema inmunitario, que protege frente a futuras atopias ${ }^{19-21}$.

Pero de entre los distintos elementos influyentes, el más importante, sin du$\mathrm{da}$, es la edad de entrada a la guardería ${ }^{5,22,23}$. La incidencia de cuadros infecciosos durante el primer año de vida es máxima. Algunos autores ${ }^{7,24}$ demostraron que la asistencia a la guardería en los dos primeros años de vida no disminuye la incidencia de infecciones en el tercer año.

Estamos, por tanto, ante una realidad $^{25,26}$ que influye de forma decisiva en la salud diaria de los niños, en el gasto sanitario, en la aparición de resistencias antibióticas y, por ende, en las decisiones que el pediatra ha de tomar diariamente. Los estudios en nuestro ámbito son escasos, por lo que parece pertinente realizar un estudio prospectivo multicéntrico analizando diversas variables de respuesta.

El objetivo del presente estudio será analizar cómo influyen las guarderías en la aparición de infecciones, en el consu- 
mo de fármacos y en la demanda de servicios médicos.

\section{Objetivo general}

El objetivo principal es analizar si la asistencia a la guardería en nuestro medio es un factor de riesgo de aumento de la morbilidad y el consumo de recursos en niños menores de 2 años.

\section{Objetivos específicos}

1. Determinar el riesgo de infecciones en los niños menores de 2 años que acuden a la guardería.

2. Comparar el consumo de antibióticos y de broncodilatadores, así como la utilización de recursos sanitarios entre los niños preescolares que acuden a la guardería y los que no lo hacen.

3. Identificar los factores familiares y personales que pueden influir sobre la incidencia de morbilidad en los niños de 2 años y determinar el riesgo que éstos suponen.

\section{Material y métodos}

\section{Tipo de estudio}

Estudio longitudinal prospectivo de dos cohortes de niños de 0-2 años, que se diferencian exclusivamente por la asistencia o no a la guardería (factor de exposición).

\section{Población de estudio}

Ámbito: consultas de pediatría de centros de salud (CS) coordinados por el Grupo de Investigación de la AEPap.

Participantes: nueve pediatras de CS del País Vasco y 15 pediatras de Andalucía (ámbito rural y urbano). Total: 24 pediatras.

Población diana o de referencia: niños de 0 a 2 años que acuden a la consulta del pediatra de Atención Primaria (AP) de los centros colaboradores, nacidos entre el 1 de abril y el 31 de octubre de 2009, que cumplen los criterios de inclusión.

Criterios de inclusión: niños de 0 a 2 años que acuden a consulta cuyas familias consientan su inclusión en el estudio tras una información completa.

Criterios de exclusión: niños que presenten patología respiratoria grave -displasia broncopulmonar o fibrosis quística-, patología cardíaca grave que precise tratamiento quirúrgico o inmunodeficiencias graves.

Tamaño de la muestra: se ha calculado que la cantidad de casos que han de seleccionarse es de 1.025, considerando la incidencia de la neumonía (4\%) como la más importante de las infecciones que se van a estudiar, para un error muestral del $1,2 \%$ y un intervalo de confianza del $95 \%$. La muestra se am- 
pliará en un $10 \%$, hasta completar un total de 1.128 casos, para mitigar la reducción del tamaño de muestra que puede ser ocasionado por diversos motivos (pérdida del seguimiento, retirada voluntaria en la participación del estudio, etc.).

\section{Variables del estudio}

1. Variable independiente: asistencia a guardería: sí o no (cualitativa dicotómica). Esta variable define las dos cohortes.

2. Definición y medida de las variables de respuesta:

- Número de infecciones que generan consulta; variable cuantitativa discreta.

- Tipo de infección: rinofaringitis, faringoamigdalitis, otitis media agu$\mathrm{da}$, estomatitis herpética, laringitis, bronquiolitis, bronquitis aguda obstructiva, gastroenteritis aguda, neumonía, enfermedades víricas exantemáticas, conjuntivitis. Variable cualitativa policotómica.

- Número de tratamientos antibióticos. Variable cuantitativa discreta.

- Número de tratamientos con broncodilatadores. Variable cuantitativa discreta.

- Consumo de recursos: hospitalizaciones, número de consultas a urgencias, número de consultas a
AP. Todas son variables cuantitativas discretas.

3. Edad de entrada a la guardería medida en meses. Se estratificarán los niños según la edad de entrada en: menores de 6 meses, entre $6 y$ 12 meses y entre 12 y 24 meses.

4. Variables de caracterización:

- Familiares:

- Padre/madre: edad (variable cuantitativa continua). Nivel de estudios: sin estudios, primarios, secundarios, universitarios (variables cualitativas dicotómicas). Ocupación. Escalas de ocupación. Tabaquismo (variable cualitativa dicotómica). Asma: sí/no (variable cualitativa dicotómica). Alergia respiratoria: sí/no (variable cualitativa policotómica).

- Hermanos: número (variable cuantitativa discreta). Escolarización: sí/no (variable cualitativa dicotómica). Asma: sí/no (variable cualitativa dicotómica).

- Personales:

- Sexo: hombre/mujer (variable cualitativa dicotómica).

- Período neonatal: edad gestacional (variable cuantitativa continua). Peso de recién nacido (variable cuantitativa continua). 
Ingreso hospitalario: sí/no (variable cualitativa dicotómica).

- Lactancia materna hasta los 4 meses: sí/no (variable cualitativa dicotómica).

- Calendario vacunal:

- Obligatorio: sí/no (variable cualitativa dicotómica). Hay que tener en cuenta que participan dos comunidades autónomas con diferentes calendarios vacunales.

- Opcional: rotavirus: sí/no (variable cualitativa dicotómica). Neumococo: sí/no (variable cualitativa dicotómica). Varicela: sí/no (variable cualitativa dicotómica). Gripe: sí/no (variable cualitativa dicotómica).

\section{Recogida de los datos}

Los datos se obtendrán de la historia clínica informatizada y de las entrevistas programadas a los padres. Las variables de caracterización se recogerán en la primera visita y las variables de respuesta a los 6, 12, 18 y 24 meses de edad.

Entrada y gestión informática de los datos recogidos de la historia clínica informatizada: se realizará una base de datos en formato electrónico, y el análisis estadístico se llevará a cabo mediante el programa estadístico EPIDAT $^{\oplus}$.

\section{Análisis estadístico}

Se realizará un análisis descriptivo de las variables con estimación puntual e intervalo de confianza del $95 \%$; se tratarán las variables continuas como medias, la desviación estándar o las medianas según la distribución de la variable. Las variables categóricas se presentarán en frecuencias y porcentajes.

Para analizar las diferencias entre el número de infecciones según la edad del niño al entrar en la guardería se realizará un test de Anova, siempre que se satisfagan las condiciones de normalidad y homocedasticidad. En caso contrario se aplicarán los correspondientes test no paramétricos. Se actuará de la misma manera para estudiar las diferencias con las variables: tipo de infección, consumo de antibióticos y de broncodilatadores y utilización de recursos sanitarios.

Para comparar el consumo de antibióticos y de broncodilatadores, así como la utilización de recursos sanitarios entre los niños preescolares que acuden a la guardería y aquellos que no lo hacen, se aplicará el test de la T de Student siempre que se satisfaga la condición de normalidad. En caso contrario se aplicará el correspondiente test no paramétrico.

Se realizará un análisis multivariante de regresión lineal paso a paso para 
identificar aquellos factores personales y familiares que se pueden considerar como variables predictoras del número de infecciones controlando los posibles factores de confusión e interacciones.

Se trabajará con un nivel de confianza del $95 \%$ y se considerarán, pues, los valores de $p$ inferiores a 0,05 como estadísticamente significativos.

\section{Limitaciones y posibles sesgos}

1. Al tratarse de un estudio de seguimiento, habrá una pérdida inevitable de casos. Para mitigar este sesgo de selección se ha ampliado el tamaño de muestra necesario en un $10 \%$.

2. Sesgo de memoria: al ser la fuente de información la entrevista clínica, estaremos sujetos a la memoria de los padres.

3. Existen factores dependientes de la guardería, como el número de niños por aula, las medidas higiénicas establecidas, el número de horas de asistencia o el número de cuidadores por niño de probable influencia que no están sujetos a estudio.

4. Sesgo del observador, al no ser posible el cegamiento, ya que el investigador es también quien decide la actitud terapéutica.

5. Al recogerse niños nacidos durante 6 meses, no se controlan la estacionali- dad y su influencia en la epidemiología de las enfermedades infecciosas, aunque el impacto podría quedar amortiguado al tratarse de un estudio prospectivo.

6. Si un niño que inicialmente asistía a la guardería dejara de hacerlo durante el estudio, saldría de éste, aunque habría que tener en cuenta su período asistencial para el cálculo de la densidad de incidencia.

7. La edad de entrada a la guardería es un factor determinante probable en el impacto de la patología infantil. Se intentará controlar dicho factor con la estratificación según la edad.

8. Sesgo de clasificación. Una de las limitaciones del estudio está constituida por los niños que no acudían a la guardería y que terminan asistiendo a lo largo del período de estudio. Para ello se van a realizar los análisis en tres momentos: a los 6, a los 12 y a los 24 meses. Además, al finalizar la recogida de datos se va a crear una nueva variable que recoja si se ha asistido a la guardería más o menos de un año.

\section{Organización del estudio. Cronograma}

- Octubre de 2009: inicio del estudio y recogida de datos de todos los niños nacidos desde el 1 de abril hasta el 31 de octubre de 2009. 
- Mayo de 2010: recogida de datos (6 meses).

- Octubre de 2010: recogida de datos (12 meses).

- Mayo de 2011: recogida de datos (18 meses).

- Reuniones periódicas con evaluaciones bimensuales.

- Fin del estudio: 2011 (datos de los niños que cumplen 2 años en octubre de 2011).

\section{Consentimiento informado y aspectos éticos}

Se utilizará el modelo normalizado de consentimiento informado aprobado por la Comisión de Ética en el caso de que el distrito/área correspondiente tenga un formato especial, junto con un documento independiente que facilite al paciente toda la información necesaria sobre el estudio (incluido el objetivo del estudio y los beneficios esperados).

El consentimiento informado a los padres incluirá una afirmación explícita de acatamiento y cumplimiento de la normativa legal y los aspectos éticos. En las hojas de recogida de datos (encuestas) y en las bases de datos que se generen a partir de ellas, en cumplimiento de la Ley 15/1999 de Protección de Datos, se separarán los datos personales (nombre, números de identificación, etc.) de los datos clínicos. El investigador principal es el responsable de su custodia.

Aplicabilidad y utilidad práctica de los resultados

Al provenir de la realidad de nuestro medio, los resultados pueden ayudar a dar un asesoramiento correcto a los padres sobre el cuidado idóneo de sus hijos, con argumentos de base científica, incluyendo recomendaciones en el Programa de Salud Infantil.

El estudio sobre el consumo de recursos sanitarios podría orientar acerca del adecuado empleo de las ayudas sociales en el caso de que las guarderías realmente influyeran sobre ellos.

La prevalencia o no de determinadas infecciones podría ayudar a replantear las políticas autonómicas hacia la homogenización de los calendarios vacunales.

\section{Definiciones de infecciones}

A continuación se exponen los criterios correspondientes a los procesos patológicos considerados en este trabajo siguiendo el Tratado de Pediatría Nelson.

- Bacteriemia: aislamiento de bacterias en el hemocultivo. Puede ser transitoria o ser la extensión potencialmente grave de una infección bacteriana invasiva. 
- Bronquiolitis: (11-12\% de menores de 2 años). Enfermedad estacional que afecta a la vía respiratoria baja del lactante. El virus respiratorio sincitial es la causa más frecuente. Suele venir precedida de una infección respiratoria alta con fiebre. Posteriormente se produce dificultad respiratoria con tos sibilante paroxística, disnea e irritabilidad. La auscultación puede evidenciar crepitantes finos, sibilancias y alargamiento espiratorio. La radiografía de tórax puede mostrar pulmones hiperinsuflados con atelectasias parcheadas.

- Bronquitis aguda: la bronquitis aguda suele venir precedida por una infección alta viral. Posteriormente aparece o no tos productiva. Puede existir febrícula y fiebre. En la exploración pueden aparecer crepitantes y sibilancias dispersas. Los niños mayores pueden presentar dolor torácico. La radiografía de tórax puede ser normal o mostrar un aumento de las líneas bronquiales.

- Conjuntivitis: la conjuntivitis aguda purulenta presenta hiperemia conjuntival, edema, exudado purulento así como molestias oculares variables. La conjuntivitis vírica se caracteriza por secreción acuo- sa. Es frecuente la existencia de folículos en la conjuntiva palpebral.

- Enfermedades víricas exantemáticas: cuadros clínicos sugestivos de infecciones por enterovirus (coxsackie, echo), herpes virus hominis tipo 6 y 7, adenovirus, parvovirus B19, sarampión, rubeola, virus de Epstein Barr, virus herpes simple y virus varicela-zóster.

- Faringitis aguda: la faringitis viral de inicio gradual puede presentar rinorrea, tos y diarrea. La faringitis estreptocócica se manifiesta de forma rápida, con dolor de garganta y fiebre. Pueden existir petequias en el paladar blando. Los ganglios cervicales anteriores son dolorosos y están aumentados de tamaño.

- Faringoamigdalitis vírica: la mayoría de los episodios de faringoamigdalitis tienen origen vírico. La faringe aparece enrojecida y las amígdalas hipertróficas pueden revestirse de exudado amarillentosanguinolento.

- Faringoamigdalitis bacteriana: el estreptococo betahemolítico del grupo A es la causa bacteriana más frecuente. Se caracteriza por dolor de garganta, fiebre y escalofríos, malestar, odinofagia, dis- 
fagia, otalgia referida, cefalea y dolores musculares. Los ganglios linfáticos cervicales se encuentran aumentados de tamaño. Las amígdalas se encuentran eritematosas y aumentadas de tamaño, existe exudación amigdalar o faríngea, sequedad lingual y en los ganglios yugulodigástricos se refiere dolor.

- Gastroenteritis aguda: infección del tracto gastrointestinal, cuyas manifestaciones básicas son diarrea, retortijones y vómitos que duran menos de 15 días.

- Laringitis: el crup suele deberse a un virus. La mayoría de los pacientes padece una infección respiratoria alta, con rinorrea, faringitis, tos $y$ febrícula, que precede a la tos perruna, la ronquera y el estridor inspiratorio. A veces puede aparecer fiebre elevada. Los síntomas empeoran por la noche.

- Meningitis de líquido claro: (1,5-4 casos por 100.000 de población general). Proceso inflamatorio agudo de las meninges, generalmente autolimitado con LCR caracterizado por pleocitosis, ausencia de microorganismos en la tinción de Gram y en los cultivos bacterianos rutinarios. LCR generalmente menor de
1.000 células, predominios mononucleares, proteínas normales o ligeramente aumentadas y glucosa generalmente normal o levemente disminuida.

- Meningitis bacteriana: (50/100.000 en el segundo año de vida de nacidos vivos). Proceso inflamatorio meníngeo producido por un agente bacteriano. El diagnóstico precisa LCR con microorganismos en el Gram, cultivo positivo. Intensa pleocitosis con predominio neutrofílico, proteínas aumentadas y glucosa disminuida.

- Neumonía: (40 casos/1.000 niños/ año en menores de 5 años). Inflamación del parénquima pulmonar, con clínica de fiebre y síntomas respiratorios (tos, taquipnea, dificultad respiratoria, dolor torácico), cuyo diagnóstico precisa radiografía de tórax confirmatoria.

- Otitis media: (incidencia anual en menores de 12 meses: 43\%). Los síntomas y signos de la otitis media aguda son variables, sobre todo en lactantes y niños pequeños. Puede existir otorrea, otalgia, fiebre, irritabilidad, otros síntomas sistémicos o incluso puede descubrirse la enfermedad en un reconocimiento médico rutinario. 
- Resfriado común: es una enfermedad viral caracterizada por la existencia de rinorrea y obstrucción nasal, con signos y síntomas sistémicos leves o inexistentes.

- Sepsis: incidencia de enfermedad meningocócica en lactantes 26,4: 100.000. Bacteriemia, hipotensión y síndrome de respuesta inflamatoria sistémica: hipertermia o hipotermia, taquicardia, taquipnea y aumento o descenso de leucocitos.

- Gripe: creemos difícil el diagnóstico de la enfermedad por la edad de los pacientes, pero dada la situación, en el caso de que se diagnostique (cultivo, entorno familiar, etc.) se incluirá entre los procesos patológicos.

\section{Encuesta estudio: escuela infantil}

N. ${ }^{\circ}$ AN o N. ${ }^{\circ}$ de afiliación a la Seguridad Social. Nombre. Código.

En las hojas de recogida de datos (encuestas) y en las bases de datos que se generen a partir de éstas, en cumplimiento de la Ley 15/1999 de Protección de Datos, se separarán los datos personales (nombre, número de la Seguridad Social, etc.) de los datos clínicos. El investigador principal es el responsable de su custodia.

\section{Primera visita}

- Código.

- Antecedentes personales:

- Lugar de nacimiento/lugar de residencia. Fecha de nacimiento. Sexo: hombre/mujer. Hermanos. Lugar que ocupa. Período neonatal: edad gestacional (EG). Peso de recién nacido (RN). Normal: sí/no. Ingreso: sí/no. UCl: sí/no.

- Antecedentes familiares:

- Padre: edad. Nivel de estudios. Ocupación. Situación laboral. Tabaquismo: sí/no. Asma: sí/no. Alergia: sí/no. Tipo.

- Madre: edad. Nivel de estudios. Ocupación. Situación laboral. Tabaquismo: sí/no. Asma: sí/no. Alergia: sí/no. Tipo.

- Hermanos: edad. Escolarización. Atopia: asma; alergia: alimentaria, cutánea. (Añadir más hermanos si fuera necesario.)

- Cuidador: edad. Nivel de estudios. Ocupación. Tabaquismo: sí/no.

- Revisiones: 6, 12, 18 y 24 meses

- Código.

- Calendario vacunal: obligatorio: sí/no. Anotar la que falte. Opcional: rotavirus: sí/no/número de dosis. Neumococo: sí/no/nú- 
mero de dosis. Varicela: sí/no. Gripe: sí/no.

- Edad de inicio de la asistencia a la escuela infantil (EI).

- Asistencia actual a la El: sí/no.

- Lactancia materna: sí/no. Hasta cuándo.

- Tratamiento: edad a la que se tomó el primer antibiótico. Número de ciclos antibióticos. Corticoides: oral: sí/no. Inhalados: sí/no. BCD: oral: sí/no. Inhalado: sí/no. Montelukast: sí/no.

- Asistencia a urgencias: sí/no. Número de ocasiones.

- Asistencia a consulta: sí/no. Número de ocasiones.

- Procesos patológicos (enfermedades desde la visita anterior).

\section{Consentimiento informado}

Se está realizando un proyecto de investigación titulado Influencia de la asistencia a guarderías sobre la morbilidad y el consumo de recursos sanitarios en niños entre 0-2 años de edad.

Se va a estudiar a niños que asisten a la guardería y a niños que no lo hacen para comparar el número de infecciones que presentan.

Se van a recoger datos sobre su hijo y las enfermedades que presenta durante los 2 primeros años de vida.

En ningún caso se realizarán pruebas complementarias ni se recomendarán tratamientos no indicados para la enfermedad que presente su hijo.

La participación de su hijo es voluntaria y podrá retirarlo del estudio cuando lo crea oportuno.

En todo momento los datos personales de su hijo se tratarán de forma confidencial siguiendo la normativa legal vigente en España (Ley 15/99 de Protección de Datos de carácter personal).

Esperamos que esta iniciativa sea de su interés y podamos contar así con su apoyo y colaboración.

Si precisa más información, por favor, pregunte a su médico.

Nombre del padre/madre: ... Doy mi conformidad para que mi hijo (nombre) participe en dicho estudio.

Firma del padre/madre. Firma del médico. 


\section{Bibliografía}

1. Encuesta de Población Activa. Módulo de conciliación entre la vida laboral y familiar [consultado el 23/03/2008]. Disponible en www.ine.es/ daco/daco42/daco4211/modunac05.xls

2. Pickering LK. Cuidados infantiles y enfermedades transmisibles. En: Behrman RE, Kliegman RM, Jenson HB, eds. Nelson Tratado de Pediatría. 17. ${ }^{\text {a }}$ ed. en esp. Madrid: Elsevier; 2006.

3. Bradley LH, Vandell DL. Child care and the well-being of children. Arch Pediatr Adolesc Med. 2007;161(7):669-76.

4. Colmes SJ, Morrow AL, Pickering LK. Childcare practices: effects of social change on the epidemiology of infectious diseases and antibiotic resistence. Epidemiol Rev. 1996;18(1):10-28.

5. Ball TM, Holberg CJ, Aldous MB, Martínez $F D$, Wright AL. Influence of attendance at day care on the common cold from birth through 13 years of age. Arch Pediatr Adolesc Med. 2002;156: 121-6.

6. Celedon JC, Litonjua AA, Weiss ST, Gold DR. Day care attendance in the first year of life and illnesses of the upper and lower respiratory tract in children with a family histoy of atopic. Pediatrics. 1999;104:495-500.

7. Holberg CJ, Wright AL, Martínez FD, Morgan WJ, Taussing LM. Child day care, smoking by carregivers, and lower respiratory tract illness in th first 3 years of life. Group Health Medical Associates. Pediatrics. 1993;91:885-92.

8. Kooproan LP, Smit HA, Heijnen MI, Wijga A, Van Strinen RT, Kerkhof $M$, et al. Respiratory infections in infants: interaction of parental allergy, child care and siblings. The PIAMA study. Pediatrics. 2001;108:943-8.

9. Paradise JL, Rockette HE, Colbora DK, Bernard BS, Smith CG, Kurs-Lasky M, et al. Otitis media in 2253 Pitsburg-area infants: prevalence and risk factors during the first two years of life. Pediatrics. 1997;99:318-33.

10. Barlett AV, Moore M, Gary GW, Starko KM, Erbea JJ, Meredith BA. Diarrheal illness among infants and toddlers in day care centers II. Comparison with day care homes and households. J Pediatr. 1985;107:503.

11. Louhiala PJ, Jaakkola $N$, Ruotsalainen R, Jaakkola JJ. Day-care centers and diarrhea: a public health perspective. J Pediatric. 1997;131(3):476-9.

12. Skull SA, Ford-Jones EL, Kulin NA, Einarson TR, Wang EL. Child care Center Staff contribute to Physician visists and pressure for antibiotic prescription. Arch Pediatr Adolesc Med. 2000;154: 180-3.

13. Silverstein M, Sales AE, Koepsell TA. Health care utilization and expenditure associated with child care attendance: a nationally representative sample. Pediatrics. 2003;111:e371-5.

14. Thrane N, Olesen C, Sondergaard C, Schonheyder MC, Sorensen $\mathrm{H}$. Influence of day care attendance on the use of systematics antibiotics in 0 to 2 years old children. Pediatrics. 2001;107(5): e76.

15. Montiano Jorge J, Ocio Ocio I, Díez López I, Matilla Fernández A, Bosque Zabala A. ¿Qué pasaría si cerrasen las guarderías? An Pediatr (Barc). 2006;65(6):556-60.

16. Ojembarrena Martínez E, Fernández de Pinedo Montoya R, Lafuente Mesanza P, Corera Sánchez M. Papel de la guardería y de la escolarización precoz en la incidencia de enfermedades infecciosas. An Esp Pediatr. 1996;45:45-8.

17. Lafuente Mesanza P, Lizarraga Azparren MA, Ojembarrena Martínez E, Gorostiza Garay E, Hernaiz Barandiarán JR. Escolarización precoz e incidencia de enfermedades infecciosas en niños menores de 3 años. An Pediatr (Barc). 2008;68:30-8.

18. National Institute Of Child Health and Human Development Early Child Care Research Net- 
work. Child care and common communicable illnesses. Arch Pediatr Adolesc Med. 2001;155:481-8.

19. Infante Rivard C, Amre D, Gautrin D, Malo JL. Family Size, Day care Attendance, and Breastfeeding in relation to the incidence of Childwood Asthma. Am J Epidemiol. 2001;153:653-8.

20. Slack-Smith LM, Read AW, Stanley FJ. Experience of respiratory and allergic illness in children attending childcare. Child Care Health Dev. 2002;28(2):171-7.

21. Celedon JC, Litonjua AA, Ryan L, Weiss ST, Gold DC. Day Care Attendance, respiratory Tract Illnesses, Wheezing, Asthma, and total serum IgE level in Early Childwood. Arch Pediatr Adolesc Med. 2002;156:214-45.

22. Robinson J. Infectious Diseases in schools and child Care facilities. Pediatr Rev. 2001;33(2): 39-46.

23. Nafstad $P$, Hagen JA, Oie L, Magnus P, Ja- akkola JK. Day care centres and respiratory health. Pediatrics. 1999;103:753-8.

24. National Institute of Child Health and Human Development Eary Child Care Research Network. Child Care and common communicable IIIness in Children aged 37 to 54 months. Arch Pediatr Adolesc Med. 2003;157:196-200.

25. Ochoa Sangrador C, Barajas Sánchez MV, Muñoz Martín B. Relación entre la asistencia a guarderías y enfermedades infecciosas agudas en la infancia. Una revisión sistemática. Rev Esp Salud Pública. 2007;81(2):113-29.

26. Martinón $F$, Bernaola Iturbe $E$, Jiménez Sánchez F. ¿Por qué hay más empiemas pediátricos en España? An Pediatr (Barc). 2008;68:15864.

27. Behrman RE, Kliegman RM, Jenson HB. Nelson Tratado de Pediatría. 17. edición. Madrid: Elsevier; 2006. 